Egyptian Poultry Science Journal

http://www.epsaegypt.com

ISSN: 1110-5623 (Print) - 2090-0570 (On line)

\title{
GENETIC EVALUATION OF SOME ECONOMIC TRAITS IN A MATERNAL LINE OF RABBITS
}

\author{
Hanaa* A. Moustafa., El-Raffa* A., Shebl* M.K., El-Delebshany* A., Nadia \\ *** A. El-Sayed \\ * Poul. Dept., Fac. of Agric., Alexandria University \\ ** Anim. Prod. Res., Inst., Agric. Res. Center
}

Accepted: 02/02/2014

\begin{abstract}
Genetic evaluation of growth and litter traits was carried out in a line of rabbits selected for litter size at weaning. The evaluation was performed on 483 does and 10847 offspring over six consecutive years of production from 2005 to 2011, using BLUP under an animal repeatability model. The high proportions of animals with positive transmitting ability estimates for slaughter weight makes this trait much better to select for than weaning weight or daily weight gain, if we are looking for growth improvement. Whereas, for litter traits studied, Litter size at weaning seems to be the best trait to use as a selection criteria for improving the reproductive performance rather than Litter size at birth or Number born alive. Estimates of rank correlations were low between weaning weight and both of slaughter weight \& daily weight gain While, correlation among ranks of transmitting ability value between slaughter weight and daily weight gain was moderate. Genetic trends estimated as a regression coefficient of trait breeding values on year of birth, which present generation number, for growth and litter traits were about 9 and $58 \mathrm{~g} /$ year for weaning weight and slaughter weight, respectively. Whereas, for daily weight gain during the fattening period, the genetic trend increased yearly by $1.08 \mathrm{~g} / \mathrm{d}$. The value of genetic trend for litter size at weaning, which used as criteria of selection in this line, means that, we can get one kit more from each litter each 12 generations.
\end{abstract}

Key Words: Rabbits, genetic evaluation, transmitting ability, genetic trend, rank correlation

Corresponding author: mkshebl@yahoo.com 


\section{INTRODUCTION}

Rabbits seem to have a good potential as a meat producing animal, especially when its productive and reproductive ability is considered (ElRaffa, 1994). Traits reflecting prolificacies such as body weight, daily weight gain, litter size at birth and/ or at weaning and conception rate are very important for the economic meat production with rabbits.

Litter size is one of the most important elements in the production efficiency in rabbit flock. Science, litter size at birth or at weaning is an indicator of reproductive efficiency in rabbits. The ability of a doe to produce thrifty young at birth and to raise these young to weaning is the characters determining her productivity (Sorensen et al., 2001; Armero and Blasco, 1992; El-Raffa, 2005; Eady and Garreau, 2008; Moce, 2010). In this respect, Baselga et al., 1992 reported that genetic improvement of litter size would be an effective method of improving the economic efficiency in rabbit production.

Development and evaluation of sound breeding programs depend upon accurate knowledge of both environmental and genetic parameters (El-Raffa, 2005). The estimates of genetic parameters for rabbit populations raised under tropical or subtropical conditions, using recent methods of statistical analysis such as REML, animal models and large data sets are limited (Ferraz and Eler, 2000). Khalil et al. (1987) concluded that the potential for genetic improvement is largely depended on the heritability of the trait measured and its relationship with other traits of economic importance. Elamin et al (2011) reported that Heritability, which is a function of variance components, provides information about the genetic nature of a trait and is needed for genetic evaluation and selection strategies.

A breeding gain in a rabbit flock depends on the breeding value (BV) of the selected individuals. The breeding value of an individual concerns the genetic merit that an individual transmit to its offspring (Chapman, 1985). The accuracy of the individuals breeding value estimation becomes more precise together with extending the information not only by their own performance test, but also of both the full and half sibs as well as of the ancestors (Wezyk and Szwaczkowski, 1993).

Mixed model methodologies under animal models have become the method of choice to estimate breeding values, not only because they provide the best linear unbiased prediction (BLUP), but also they are used simultaneously to estimate genetic and environmental effects taking into account the relationship among animals (Henderson, 1985; Sorensen and Kennedy, 1986; Meyer, 1988). For rabbit populations under selection programs, it is a must to evaluate the individuals genetically in order to obtain the benefits from these programs. Best linear unbiased prediction (BLUP) procedure can be used to predict breeding values of animals and adjust for model fixed effects, and evaluate the random genetic effects (Harris et al., 1989). Therefore, BLUP procedure provides the most complete framework for the estimation of breeding values (Kennedy, 1991; Haggar, 1992; Morde, 1996).

The animal model procedure is also useful in determination of genetic trend or progress realized over several years (Schaefer, 1994). In this respect, genetic trends for rabbit populations have been reported by several investigations (Estany et al., 1989; Baselga et al., 1992; Ferraz et al., 1992; Rochambeau et al., 1994; Gomeze et al., 1996; Gyovai et al, 2008; Garcia and Baselga 2010). In recent years, genetic evaluation of rabbits was most often performed using an animal model (Ferraz et al., 1991; Baselga et al., 1992; Reverter et al., 1994; Youssef, 1998; Ferraz et al 1992; Lukefahr et al 1996; Lukefahr and Hamilton 1997; Rastogi et al 2000; Sorensen et al 2001; El-Deghadi 2005; Khalil et al., 2005 El-Raffa, 2005). 
The main objectives of the present study were, to evaluate genetically growth and litter traits in meat rabbits through prediction of the transmitting ability of individuals using single trait animal models, obtaining the genetic trend, and determination of rank correlations between the studied traits.

\section{Materials and Methods}

Data of the present study were collected at the nucleus breeding rabbit farm of Poultry Research Center, Faculty of Agriculture, Alexandria University spreading over six consecutive years of production from 2005 to 2011.

Population: A closed line of rabbits, $\mathrm{V}$ Line, was included in the investigation. Line $\mathrm{V}$ is a synthetic maternal line originated in 1982, and was developed at the Department of Animal Science of Universidad Polytechnic de Valencia, Valencia, Spain. In this line, Litter size at weaning was considered as the criterion for the selection goal. The method that is used to evaluate the animals is a BLUP under an animal repeatability model (Estany et al., 1989). A set of $\mathrm{V}$ Line rabbits was imported to the Poultry Research Center, Alexandria University at the end of year 1998 (El-Raffa, 2000), multiplied for five years and after that, the selection was continued under the same criterion.

Housing: During the whole period of investigation, the rabbits were housed in a windowed rabbitry, with a two level pyramid design cages having galvanized wire. The breeding animals were kept individually in the first level, whereas the growing animals were kept in the second one. After weaning, the growing rabbits were raised in collective cages ( 5 per cage). All the flock was kept under the same managerial and environmental conditions.

Reproductive management: The females were first mated at the age ranging from 135 to 150 days. At the beginning of the breading season, during September, the breeding rabbits were divided into groups for within group mating. Each group was made up by three does and one buck that were chosen to avoid mating between close relatives (avoiding full-sibs, half-sibs and parent-offspring mating). Each doe was transferred to the buck's cage to be mated. The offspring were weaned at the $28^{\text {th }}$ day of age. At weaning, young rabbits were removed from doe's cages and raised in collective cages in groups of five rabbits. The kits were individually ear tagged at weaning.

Records: Numbers of records available were 483 does with 4048 mating, and 3158 litters. Total tested offspring were 10847 which include 4492 males, 3884 females, and the rest of the tested offspring was unsexed.

Studied traits: The growth traits studied were: Individual weight at weaning (28d), or weaning weight (WW, g), Individual weight at the end of the fatting period (63d) or slaughter weight ( $\mathrm{SW}, \mathrm{g}$ ), Individual daily weight gain during the fatting period (28-63d) (DWG, g/d). Whereas, the litters traits under consideration were: Total litter size at birth (LSB), Number born alive (NBA), Litter size at weaning (LSW).

Statistical analysis: Estimates of variance components for studied traits were obtained using restricted maximum likelihood (REML) method (Pattern \& Thompson, 1971; Rao, 1972) via the Mixed Model Equation using variance component procedure described by the Statistical Analysis System program (SAS, version 9.2 , 2004). This method is an iterative method that solving the equations of random effect in economical procedure (Johan et al., 1984). In this procedure, iterations are continued using the estimators of sire and error variance (in case of sire model) from the preceding round of iteration until the estimates are stabilized (Youssef, 1998).

Estimates of variance components were for sire, doe and residual random effects for growth traits studied. While, for litter traits under consideration, the variance components were estimated for 
sire of doe, dam of doe and residual random effects.

The basic form of the general mixed linear model is

$$
\mathrm{Y}=\mathrm{Xb}+\mathrm{Z} \mu+\mathrm{e}
$$

\section{Where:}

$\mathrm{Y}$ an $(\mathrm{n} \times 1)$ observational vector, $\mathrm{n}=$ number of records.

$\mathrm{X} \quad \mathrm{n} \quad \mathrm{x} \quad \mathrm{p}$ incidence matrix for fixed effects, $\mathrm{P}=$ number of levels for fixed effects.

b px1 vector of fixed effects, (the fixed effects considered for each trait.

$\mathrm{Z} n \times \mathrm{q}$ incidence matrix for random effects, $q=$ number of levels for random effects. $\mu \quad \mathrm{q} \times 1$ vector of random effects.

e $\mathrm{n} \times 1$ vector of random residual effects.

The general representation of the model used is as follows:

$\mathrm{Y}=\mathrm{x} \mathrm{b}+\mathrm{Z}_{1} \mathrm{~s}+\mathrm{Z}_{2} \mathrm{~d}+\mathrm{e}$

Where model terms $s, d$ and e are random effects of sire (or sire of doe), doe (or dam of doe) and individual (or litter). They were assumed to be normally and independently distributed (no relationships exist between mated sires and dams) with zero means and variances $\sigma_{\mathrm{s}}^{2}, \sigma_{\mathrm{d}}^{2}$ and $\sigma_{\mathrm{e}}^{2}$, respectively.

Using the matrix notation, the mixed model equation (MME) of the model can be given as follows:

$\left|\begin{array}{lll}\mathrm{X}^{\prime} \mathrm{X} & \mathrm{X}^{\prime} \mathrm{Z}_{\mathrm{S}} & \mathrm{X}^{\prime} \mathrm{Z}_{\mathrm{d}} \\ \mathrm{Z}_{\mathrm{S}}{ }^{\prime} \mathrm{X} & \mathrm{Z}_{\mathrm{S}} \mathrm{Z}_{\mathrm{S}}+\mathrm{I} \lambda_{1} & \mathrm{Z}_{\mathrm{S}}{ }^{\prime} \mathrm{Z}_{\mathrm{d}} \\ \mathrm{Z}_{\mathrm{d}} \mathrm{X} & \mathrm{Z}_{\mathrm{d}} \mathrm{Z}_{\mathrm{S}} & \mathrm{Z}_{\mathrm{d}}{ }^{\prime} \mathrm{Z}_{\mathrm{d}}+\mathrm{I} \lambda_{2}\end{array}\right|\left|\begin{array}{c}\mathrm{b} \\ \mu_{1} \\ \mu_{2}\end{array}\right|=\left|\begin{array}{c}\mathrm{X}^{\prime} \mathrm{Y} \\ \mathrm{Zs}^{\prime} \mathrm{Y} \\ \mathrm{Z}_{\mathrm{d}}{ }^{\prime} \mathrm{Y}\end{array}\right|$

Where:

$\Lambda_{1} \quad$ represents the ratio of known variances $\left(\sigma_{\mathrm{e}}^{2} / \sigma_{\mathrm{s}}^{2}\right)$

$\Lambda_{2}$ represents the ratio of known variances $\left(\sigma_{\mathrm{e}}^{2} / \sigma_{\mathrm{d}}^{2}\right)$

I represents identity matrix

Heritability was estimated as four times the ratio of sire observational variance component to total phenotypic variance (summation of sire, doe and residual variance components) in case of growth traits. Whereas, for litter traits, the estimates of heritability was as four times the ratio of sire of doe observational variance component to total phenotypic variance (summation of sire of doe, dam of doe and residual variance components). Phenotypic and genetic correlations between studied traits were estimated by multivariate analysis of variance with SAS program.

Transmitting ability for growth traits and litter traits studied were estimated using animal model program, Multiple Trait Derivative- Free Restricted Maximum Likelihood program (MTDFREML computer packaged) written by Boldman et al., 1995. The BLUP of breeding value estimates obtained take into account the numerator relationship matrix among animals $\left(\mathrm{A}^{-1}\right.$ matrix). Estimates of variance components $\left(\sigma^{2}{ }_{\mathrm{s}} \& \sigma_{\mathrm{e}}^{2}\right)$ obtained by REML procedure were used in the Animal Model program as $\left(\sigma_{\mathrm{A}}^{2} \& \sigma_{\mathrm{e}}^{2}\right)$ guessed values (starting values) to estimate the breeding values of animals for the studied traits.

The general mixed linear model equation is $\mathrm{Y}=\mathrm{Xb}+\mathrm{Za}+\mathrm{e}$

All symbols of this model were defined previously. 
The mixed model equations (MME) of the animal model explained above were:

$$
\left|\begin{array}{ll}
\mathrm{X}^{\prime} \mathrm{X} & \mathrm{X}^{\prime} \mathrm{Z} \\
\mathrm{Z}^{\prime} \mathrm{X} & \mathrm{Z}^{\prime} \mathrm{Z}+\mathrm{A}^{-1} \alpha
\end{array}\right|\left|\begin{array}{c}
\mathrm{b} \\
\mu_{1}
\end{array}\right|=\left|\begin{array}{l}
\mathrm{X}^{\prime} \mathrm{Y} \\
\mathrm{Z}^{\prime} \mathrm{Y}
\end{array}\right|
$$

Where:

$\mathrm{A}^{-1}$ is the inverse of the numerator relationship matrix $\& \alpha=\sigma_{\mathrm{s}}^{2} / \sigma_{\mathrm{e}}^{2}$

Genetic trends were estimated for growth and litter traits studied. The trend was obtained by, first estimating the breeding values by single trait Animal Model for each trait, mean of expected breeding values were computed. The regression of these breeding values on generation was used to estimate genetic trend.

Spearman rank correlations among ranks of predicted transmitting ability estimates for the studied traits were computed using proc correlation procedure described by SAS program (SAS version 9.2, 2004).

\section{Results and Discussion}

\section{I-Growth traits:}

\section{1- Descriptive data:}

Slaughter weight obtained in the current study (Table 1) seems to be suitable for the costumers needed in Egypt. Therefore, marketing $\mathrm{V}$ line rabbits at 9 weeks is quietly recommended under Egyptian environmental conditions.

Table (1): Descriptive data (means and S.E.) for growth traits of V line rabbit.

\begin{tabular}{|l|l|l|l|}
\hline \multicolumn{1}{|c|}{ Trait } & \multicolumn{1}{|c|}{ N } & \multicolumn{1}{c|}{ Mean } & \multicolumn{1}{c|}{ S.E. } \\
\hline WW $(\mathrm{g})$ & 10847 & 580.2 & 1.73 \\
SW $(\mathrm{g})$ & 8495 & 1617.1 & 3.18 \\
DWG (g/day) & 8351 & 31.26 & 0.09 \\
\hline
\end{tabular}

WW = weaning weight $\quad \mathrm{SW}=$ slaughter weight $\quad \mathrm{DWG}=$ daily weight gain

\section{2- Genetic parameters:}

Estimates of heritability for growth traits studied ranged from moderate to high (Table 2). This may be due to selection for litter size at weaning could possibly be caused the wide genetic variation of the genetic base for this line in traits characterizing growth. The heritability of these traits in Line $\mathrm{V}$ raised in Valencia has been previously estimated by Garcia and Baselga (2002). They got the same estimate for SW, but the estimates of WW was 0.2 and for DWG 0.2. It must be noted that, the higher values of heritabilities obtained for daily weight gain than this for marketing weight suggested that daily weight gain may be more heritable than body weight at marketing. Thus, it may conclude to use daily weight gain as criteria of selection if we are looking to improve growth performance in rabbit flocks. However, the variations between heritabilities estimates reported in the literature could possibly be due to method of estimation used, type of corrections made to the data (statistical models used) and number of observation available for the investigation. Also, the genetic make-up of the flock and the selection applied will affect the value of the heritability estimate.

The genetic correlation between SW and each of WW and DWG were high and 
positive being $0.73 \& 0.72$, respectively. While, moderate positive genetic correlation was found between WW \& DWG with value of 0.42 (Table 2). Daily weight gain (DWG) from weaning to slaughter was phenotypically high positive correlated with slaughter weight with value of 0.68 but not with weaning individual weight (0.12). In agreement with these results, Khalil and Khalil (1991), Moura et al. (1991) and El-Raffa (1994 \& 2005) obtained high positive phenotypic correlation between body weights of rabbits at different ages. These results support that selection for improving the daily weight gain from 4 to 9 weeks would be expected to result in an increase of body weight at 9 weeks of age.

Table (2): Estimation of genetic parameters for growth traits in V line rabbit, heritability (in diagonal), genetic correlations (above diagonal) and phenotypic correlations (below diagonal)

\begin{tabular}{|l|l|l|l|}
\hline \multicolumn{1}{|c|}{ Trait } & \multicolumn{1}{c|}{ WW } & \multicolumn{1}{c|}{ SW } & \multicolumn{1}{c|}{ DWG } \\
\hline WW & $0.47 \pm 0.00003$ & $0.73 \pm 0.00003$ & $0.42 \pm 0.00004$ \\
SW & $0.46^{* *}$ & $0.30 \pm 0.00003$ & $0.72 \pm 0.00003$ \\
DWG & $0.12^{* *}$ & $0.68^{* *}$ & $0.42 \pm 0.00003$ \\
\hline
\end{tabular}

WW = weaning weight $\quad \mathrm{SW}=$ slaughter weight $\quad \mathrm{DWG}=$ daily weight gain

$* * \mathrm{P} \leq 0.01$

\section{II-Litter traits:}

\section{1- Descriptive data:}

It is also apparent from these results that simple means for litter size traits were $9.25,8.29 \& 5.38$ for litter size at birth, number of kits born alive and litter size at weaning, respectively (Table 3). These results may indicate good maternal ability for does in Line $\mathrm{V}$, that reflect higher reproductive performance for this Line

Table (3): Descriptive data (means and S.E.) for litter traits of V line rabbit.

\begin{tabular}{|l|l|l|l|}
\hline \multicolumn{1}{|c|}{ Trait } & N & Mean & S.E. \\
\hline LSB & 3144 & 9.25 & 0.06 \\
NBA & 3158 & 8.29 & 0.07 \\
LSW & 3136 & 5.38 & 0.06 \\
\hline
\end{tabular}

$\mathrm{LSB}=$ Litter size at birth $\quad \mathrm{NBA}=$ Number born alive

$\mathrm{LSW}=$ Litter size at weaning

\section{2- Genetic parameters:}

It is apparent from these results that litter sizes traits up to weaning are both genetically and phenotypically positively correlated (Table 4). Similar findings were observed by many researchers (Khalil et al., 1987; Afifi et al., 1992; El-Raffa, 1994). The higher values of genetic correlations between litter size traits indicate that these traits were controlled by the same genes. The high positive genetic 
correlations obtained in the current study are expected because of litter size traits studied are very close. These results are in agreement with those obtained by Ferraz and Eler (2000) and El-Raffa (2005). The knowledge of this association can be used in planning for more accurate selection programs taking into consideration the direction and size of the association between traits.

The phenotypic correlations between litter traits studied are positive but smaller in value than the genetic correlation
(Table 4). The smaller values of phenotypic correlation than the genetic ones may be due to the adverse environmental effect on the association between these traits. However, large variability in values of phenotypic correlation between litter traits were reported in the literature. This variability of estimates between different authors could be attributed to the differences in environment and level of productivity between different rabbit flocks.

Table (4): Estimation of genetic parameters for litter traits in V line rabbit, heritability (in diagonal), genetic correlations (above diagonal) and phenotypic correlations (below diagonal)

\begin{tabular}{|l|l|l|c|}
\hline \multicolumn{1}{|c|}{ Trait } & \multicolumn{1}{c|}{ LSB } & \multicolumn{1}{c|}{ NBA } & \multicolumn{1}{c|}{ LSW } \\
\hline LSB & $0.02 \pm 0.0002$ & $0.79 \pm 0.0019$ & $0.68 \pm 0.0024$ \\
NBA & $0.48 * *$ & $0.04 \pm 0.0002$ & $0.89 \pm 0.0007$ \\
LSW & $0.39 * *$ & $0.47 * *$ & $0.10 \pm 0.0003$ \\
\hline
\end{tabular}

$\mathrm{LSB}=$ Litter size at birth $\quad \mathrm{NBA}=$ Number born alive $\quad \mathrm{LSW}=$ Litter size at weaning $* * \mathrm{P} \leq 0.01$

\section{III- Genetic evaluation of rabbits:}

\section{1- Transmitting ability:}

The minimum and maximum transmitting ability estimates and their ranges for all individuals for growth and reproductive traits studied are shown in Table 5. The ranges of transmitting ability for all animals estimated for growth traits were 512, $878 \& 22.4$ for WW, SW \& DWG, respectively, whereas, these values obtained for litter traits were $0.22,0.62 \&$ 1.80 for LSB, NBA \& LSW, respectively.
These variations can introduce the possibility of making the correct culling decision and selecting the best rabbits from those having positive estimates of transmitting ability for growth and/ or litter size traits. In this respect, El-Raffa (2000) working on $\mathrm{V}$ line rabbits, found range of transmitting ability for LSB higher than this obtained in this study, and lower range of transmitting ability for LSW compared with the range presented in the current study. 
Table (5): Minimum, Maximum, and Range of transmitting ability estimates for animals, estimated by single trait animal model for studied traits.

\begin{tabular}{|l|l|l|l|l|}
\hline \multicolumn{1}{|c|}{ Trait } & \multicolumn{1}{c|}{ N } & \multicolumn{1}{c|}{ Minimum } & \multicolumn{1}{c|}{ Maximum } & \multicolumn{1}{c|}{ Range } \\
\hline Growth traits & & & & \\
WW & 5536 & -253.0 & 258.8 & 511.8 \\
SW & 5536 & -465.7 & 431.8 & 897.5 \\
DWG & 5463 & -10.5 & 11.9 & 22.4 \\
Litter traits & & & & \\
LSB & 686 & -0.10 & 0.12 & 0.22 \\
NBA & 686 & -0.28 & 0.34 & 0.62 \\
LSW & 686 & -0.64 & 1.16 & 1.80 \\
WW = weaning weight & SW = slaughter weight $\quad$ DWG = daily weight gain \\
LSB= Litter size at birth
\end{tabular}

The total numbers of rabbits evaluated for each trait studied are provided in Table 6. Moreover, this table presented the number of rabbits with positive transmitting ability estimates and their percentages for each trait studied. The ratio of positive values of transmitting ability $(55,65 \& 61 \%$ for WW, SW \& DWG and 53, 56 \& $60 \%$ for LSB, NBA \& LSW) are high enough to allow for genetic improvement bearing in mind that about $25 \%$ will be selected as a parent for replacement each year. Table 7 represents the values of transmitting abilities estimates of productive and reproductive traits studied for top $25 \%$ of animals.

In view of these results, for growth traits studied, the high proportions of animals with positive transmitting ability estimates for SW makes this trait much better to select for than WW or DWG, if we are looking for growth improvement. Whereas, for litter traits studied, LSW seems to be the best trait to use as a selection criteria for improving the reproductive performance. These results may lead to a general conclusion that if a good selection plan will be adopted, positive progress will be achieved.

Table (6): Number of animals included in the genetic evaluation, number and percentage of animals with positive estimates of transmitting ability recorded by single trait animal model for studied traits.

\begin{tabular}{|l|l|l|l|}
\hline \multirow{2}{*}{\multicolumn{1}{|c|}{ Trait }} & \multirow{2}{*}{ Total number } & \multicolumn{2}{c|}{ Rabbits with Positive records } \\
\cline { 3 - 4 } & & \multicolumn{2}{|c|}{ No. } \\
\hline Growth traits & & 3023 & 54.61 \\
WW & 5536 & 3570 & 64.49 \\
SW & 5536 & 3335 & 61.05 \\
DWG & 5463 & & \\
Litter traits & & 365 & 53.21 \\
LSB & 686 & 382 & 55.69 \\
NBA & 686 & 411 & 59.91 \\
LSW & 686 & & \\
\hline
\end{tabular}

WW = weaning weight $\quad \mathrm{SW}=$ slaughter weight $\quad$ DWG = daily weight gain $\mathrm{LSB}=$ Litter size at birth $\quad \mathrm{NBA}=$ Number born alive $\quad \mathrm{LSW}=$ Litter size at weaning 
Table (7): Minimum, Maximum and range of transmitting ability estimates for top $25 \%$ of animals obtained by single trait animal model for studied traits.

\begin{tabular}{|l|l|l|l|}
\hline \multirow{2}{*}{\multicolumn{1}{|c|}{ Trait }} & \multicolumn{2}{c|}{ Top 25\% of rabbits } \\
\cline { 2 - 4 } Growth traits & \multicolumn{1}{|c|}{ Minimum } & \multicolumn{1}{c|}{ Maximum } \\
WW & 68.22 & 258.84 & 190.62 \\
SW & 90.69 & 431.80 & 341.11 \\
DWG & 2.05 & 11.97 & 9.92 \\
Litter traits & & & \\
LSB & 0.018 & 0.123 & 0.105 \\
NBA & 0.052 & 0.339 & 0.287 \\
LSW & 0.277 & 1.160 & 0.883 \\
\hline
\end{tabular}

WW = weaning weight $\quad$ SW = slaughter weight $\quad$ DWG $=$ daily weight gain

$\mathrm{LSB}=$ Litter size at birth $\quad \mathrm{NBA}=$ Number born alive $\quad \mathrm{LSW}=$ Litter size at weaning

\section{2- Rank correlation:}

Rank correlations and their significance between growths traits studied are presented in Table 8. The results show that, estimates of rank correlations were low between WW and both of SW \& DWG While, correlation among ranks of transmitting ability value between SW and DWG was moderate.

Table 9 shows the values of rank correlations and their significance between litter traits studied. It is apparent from these results, the rank correlation between LSB $\&$ NBA was high, whereas, the values of rank correlations between LSW and both of LSB \& NBA were moderate.

In view of these results, it may be concluded that litter size at weaning seems to be the most consistent trait that could be used as a selection criterion for improving reproductive performance in rabbits.

Table (8): Rank correlations among transmitting ability estimates of growth traits.

\begin{tabular}{l|l|l|l|}
\hline \multicolumn{1}{|c|}{ Trait } & \multicolumn{1}{c|}{ WW } & \multicolumn{1}{c|}{ DW } \\
\hline WW & & 0.05 & -0.08 \\
SW & & & $0.25^{* *}$ \\
DWG & & & \\
\hline WW = weaning weight & $\mathrm{SW}=$ slaughter weight $\quad$ DWG = daily weight gain \\
$* * \mathrm{P} \leq 0.01$ &
\end{tabular}

Table (9): Rank correlations among transmitting ability estimates of litter traits.

\begin{tabular}{l|l|l|l|}
\hline \multicolumn{1}{|c|}{ Trait } & LSB & \multicolumn{1}{c|}{ NBA } & \multicolumn{1}{c|}{ LSW } \\
\hline LSB & & $0.81^{* *}$ & $0.26^{* *}$ \\
NBA & & & $0.46^{* *}$ \\
LSW & & & \\
\hline LSB $=$ Litter size at birth & NBA= Number born alive LSW= Litter size at weaning \\
$* * \mathrm{P} \leq 0.01$ &
\end{tabular}




\section{3- Genetic trend:}

Genetic trends estimated as a regression coefficient of breeding values on year of birth, which present generation number, for growth and litter traits studied are provided in Table 10 and Fig. 1. The results show that, genetic trends were about 9 and $58 \mathrm{~g} /$ year for WW and SW, respectively. Whereas, for DWG during the fattening period, the genetic trend increased yearly by $1.08 \mathrm{~g} / \mathrm{d}$.

The value of genetic trend for litter size at weaning, which used as criteria of selection in this line, means that, we can get one kit more from each litter each 12 generations. Moreover, it is apparent from these results that, although the values of genetic trend for LSB and NBA were not significant, the genetic trend for LSW significantly increased with the advantage of generation number. These may reflect the improving of the performance of $\mathrm{V}$ Line does through increasing their mothering abilities, to take more care of their kits during the suckling period, year by year.

Table (10): Estimated genetic trend (linear) for growth and litter traits by generation

\begin{tabular}{|c|c|c|}
\hline Trait & Genetic trend & S.E \\
\hline \multicolumn{3}{|l|}{ Growth traits } \\
\hline WW (g) & 9.30 & 1.56 \\
\hline $\mathrm{SW}(\mathrm{g})$ & $57.65^{* *}$ & 1.99 \\
\hline DWG $(g / d)$ & 1.08 & 0.04 \\
\hline \multicolumn{3}{|l|}{ Litter traits } \\
\hline LSB & 0.0002 & 0.0003 \\
\hline $\mathrm{NBA}$ & 0.001 & 0.0009 \\
\hline LSW & $0.08 *$ & 0.003 \\
\hline \multicolumn{3}{|r|}{$\mathrm{DWG}=$ daily weight gain } \\
\hline $\mathrm{LSB}=$ Litter size at birth & $\mathrm{NBA}=$ Number born alive & \\
\hline \multicolumn{3}{|c|}{$\mathrm{LSW}=$ Litter size at weaning } \\
\hline$* \mathrm{P} \leq 0.05$ & $* * \mathrm{P} \leq 0.01$ & \\
\hline
\end{tabular}


Figure (1): genetic trend (linear) for growth and litter traits by generation

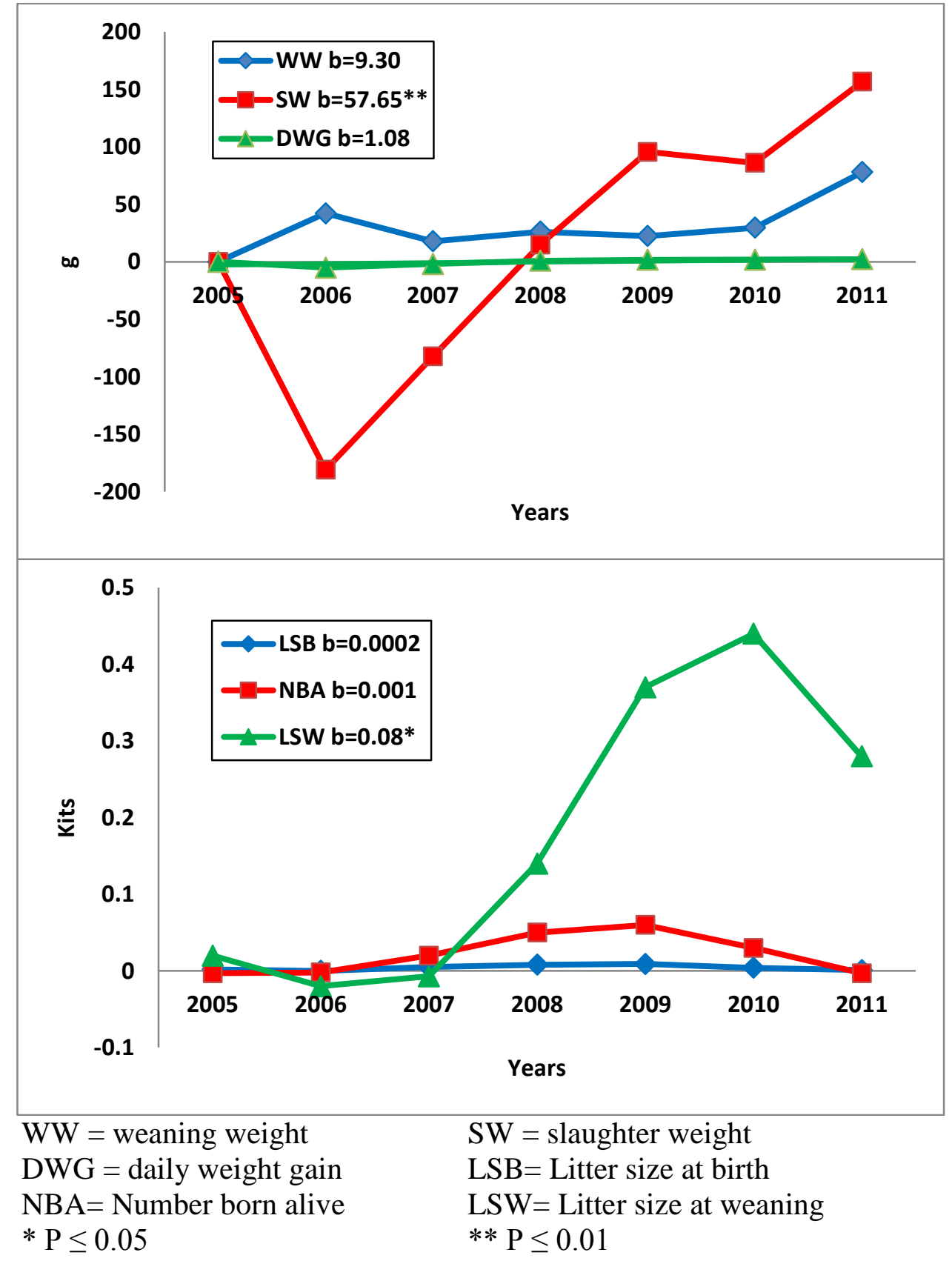

\section{CONCLUSION}

Genetic evaluation and continuous selection for the economic traits in rabbit's lines is very useful to increase its productive and reproductive performance. This will help the rabbit's producers' to increase their production and profits. 


\section{REFERENCES}

Afifi. E. A., Yamany,K.A. Marai, I. F. and El-Maghawry, A. M. (1992). Environmental and genetic aspects of litter traits in New Zealand White and Californian rabbits under the Egyptian condition. J. Appl. Rabbit Res. 15: 335-351.

Armero, Q. and Blasco A. (1992). Economic weights for rabbit selection indices. Fifth Congress of the World Rabbit Science Association. July 25-30, 1992. Oregon, U.S.A. vol. A, PP 637-642.

Baselga, M., E. Gomez, P. Cifre and Camacho, J. (1992). Genetic diversity of litter size traits between parities.In rabbits.Fifth Congress of the World Rabbit Science Association. July 25-30, 1992. Oregon, U.S.A vol. A, pp 198-205.

Boldman, K.G., Kriese, L.A. Van Vleak, L.D. Van Tassell, C.P.and Kachman S.D. (1995). Manual use of MTDFREML, A set of programs to obtain estimates of variances and covariances (DRAFT) U.S. Department of Agriculture, Agriculture Research Service.

Chapman, A.B. (1985). General and quantitative genetics.Elsevier Science publishers. B.V., New York.

Eady S.J., Garreau H. (2008) An enterprise gross margin model to explore the influence of selection criteria for breeding programs and changes to management systems.

El-Amin, K M Yousif, I A Elkhairey M $A$ and Mekki D M (2011). Heritability estimates and genetic correlations for post-weaning body weight traits in Sudanese rabbits Livestock Research for Rural Development, Volume 23, Number 11.

El-Deghady Amira S (2005). Genetic evaluation for some productive traits in rabbits. Ph.D. Thesis, Faculty of Agriculture, Banha University, Egypt.

El-Raffa, A. M. (2000). Animal model evaluation of $\mathrm{V}$ line rabbits raised under Egyptian condition. Litter size traits. Egyptian Poultry Science. Vol. 20(IV): 1003.

El-Raffa, A.M. (1994). Some factors affecting economical productive and reproductive traits in rabbits. $\mathrm{Ph}$. D. Thesis, Faculty of Agriculture, Alexandria University, Egypt.

El-Raffa, A.M. (2005). Genetic analysis for productive and reproductive traits of $\mathrm{V}$ line Rabbits raised under Egyptian conditions. Egypt. Poult. Sci., Vol. 25 (IV): 1217- 1231.

Estany, Y., Baselga, M., Blasco, A. and Camacho, J. (1989). Mixed model methodology for the estimation of genetic response to selection in litter size of rabbits. Livestock Prod. Sci., 45: 87-92.

Ferraz J.B.S., Eler J.P. (2000). Choice of animal models for estimation of genetic parameters of reproductive, growth and slaughter traits of Californian and New Zealand.

Ferraz J. B. S., Johnson, R. K and Van Vleck, L. D. (1992). Estimation of genetic trends and genetic parameters for reproductive and growth traits of rabbits raised on subtropics with animal models. J. Appl. Rabbit Res. 15: 131-142

Ferraz, J.B.S., Johnson, R.K and Eler, J.P. (1991). Genetic parameters for growth and carcass traits of rabbits. J. Appl. Rabbit Res. 14: 187.

Garcia, M.L. and Baselga, M. (2002). Estimation of correlated response on growth traits to selection in litter size of rabbits using a cryopreserved control population and genetic trends. Livestock. Prod. Sci., 78: 91-98.

Garcia, M.L. and Baselga, M. (2010). Genetic response to selection for 
reproductive performance in a maternal line of rabbits. World rabbit science, Vol. 10 (2), 71-76.

Gomaze E.A., Raffel O., Ramon J., Baselga M., (1996). A genetic study of a line selected on litter size at weaning . Proc. 6 World rabbit congress. Toulouse. Vol., 2: 289293.

Gyovai P, Nagy I, Gerencser Zs, Metzger Sz, Radnai I, Szendro Zs. (2008). Genetic parameters and trends of the thigh muscle volume in pennon white rabbits. In: Proc $9^{\text {th }}$ world rabbit Congress- June 1013, Verona-Italy 115-119.

Hagger, C. (1992). Two generations of selection on restricted best linear prediction breeding values for income minus feed cost in laying hens. J. Anim. Sci. 70(7):2045.

Harris, D. L., Lofgren, D.L Stewart T. S. and Schinckel, A. P. (1989). Adapting best linear unbiased prediction (BLUP) for timely genetic evaluation: 1 . Progeny traits in a single contemporary group for each sex. J. Anim. Sci. 67(12): 3209.

Henderson, C. R. (1985). Best Linear unbiased prediction of non-additive genetic merits in non-inbred populations. J. Anim. Sci.60: 111117.

Johan P.C., Christian L.L., Rothschild M.F., Willhan R.L. (1984). An evaluation of four procedures to rank centrally tested boars. J. Anim. Sci., 59: 934.

Kennedy, B.W. (1991). C.R. Henderson: The unfinished legacy. J. Dairy Sci. 74:4067.

Khalil M.H., García M.L., Al-Dobaib S.N., AL-Homidan A.H., Baselga M. (2005). Genetic evaluation of crossbreeding project involving Saudi and Spanish V-line rabbits to synthesize new maternal lines in Saudi Arabia: I. Pre-weaning litter, lactation traits and feeding parameters. In Proc. 4th International Conference of Rabbit Production in Hot Climate, 2005 February, Sharm El-Sheikh, Egypt, 89-99.

Khalil, M.H. and Khalil, H.H. (1991). Genetic and phenotypic parameters for weaning and preweaning body weights and gain in Bouscat and Giza White rabbits. 3. App!. Rabbit Res., 14: 44-51

Khalil, M.H., Owen, J.B and Afifi, E.A. (1987). A genetic analysis of litter traits in Bouscat and Giza White rabbits. Anim. Prod., 45: 123-134.

Luefahr, S.D., Hamilton, H.H. (1997). Heritability and repeatability estimates of maternal performance traits in purebred and crossbred does. World Rabbit Sci. 5(3), 99 105.

Lukefahr S D, Odi H B and Atakora J K A (1996). Mass selection for 70-day body weight in rabbits. Journal of Animal Science 74:1481-1489.

Meyer, K., (1988). Restricted maximum likelihood to estimate variance components for Animal Models with several random effects using a derivative-free algorithm. Genetics Selection Evaluation.21: 317.

Moce, M.L. and Santacreu, M. A. (2010). Genetic improvement of litter size in rabbits.

Morde, R.A. (1996). Linear models for the prediction of animal breeding values. $\mathrm{CAB}$ International, Biddles Ltd, Guildford, UK.

Moura, A.S.A.M.T., Polastre, R. and Carmelo, M.J. (1991). Genetic study of individual performance from weaning to slaughter in Selecta rabbits. J. App. Rabbit Res., 14: 228-234.

Patterson, H. D., and R. Thompson. (1971). Recovery of interlocks information when block sizes are unequal. Biometrical58:545-554.

Rao. C. R. (1972). Estimation of variance and covariance components in 
linear models. Journal of the American Statistical Association. 67: 112-115.

Rastogi, R.K; Lukefahr, S.D. and Lukefahr, F.B. (2000). Heritability and repeatability of litter traits based on dam records from a tropical rabbit's population in Trinidad, West Indian. 7th World Rabbit Cong., Valencia, 2000.

Reverter, A., B.L. Golden, R.M. Bourdon and J.S. Brinks (1994). Method variance components procedure: Application on the simple breeding value model. J. Anim. Sd. 72: 2247.

Rochambeau H. DE, Bolet G, Tudela F. (1994). Long term selection Comparison of two rabbit strains. Proc. $5^{\text {th }}$ World Cong. Genet. Appl. Livest. Pord. 19, 257-260.

SAS (2004). Version 9.2, SAS Institute, Inc., Cary NC, USA.

Schaeffer, L.R. (1994). Variance component estimation methods. University of Guelph, Guelph Ontario, Canada.

Sorensen, D.A. and Kennedy,B.W.
(1986). Analysis of selection experiments using mixed model methodology.. J. Anim. Sci. 68: 245.Surdeau, P., G. Matheon, and G. Perrrier, 1980. EtdueComparee de deuxrythemes de production chez la lapin de chair.Proceeding of the Second World Rabbit Congress. April, 1980. Barcelona, Spain. PP 313-321.

Sorensen, P., Kjaer, J.B., Brenoe, U.T., Su, G. (2001). Estimates of genetic parameters in Danish White rabbits using an animal model: II. Litter traits. World Rabbit Science 9:3338.

Wezyk, S. and Szwaczkowski,T. (1993). Application of animal model to the estimation of breeding value of lying hens in Poland: Present possibilities and prospects. Instytut Zootechniki Biuletynlnformacyjny 31(1-2): 3.

Youssef M.K.(1998). Genetic analysis for reproductive life of doe rabbit. Ph. D. Thesis, Faculty of Agriculture at Moshtohor, Zagazig University, Banha Branch, Egypt. 